\title{
Yesterday or Today
}

National Cancer Institute

\section{Source}

National Cancer Institute. Yesterday or Today. NCI Thesaurus. Code C136321.

The time period consisting of the current day and the preceding day. 